\title{
Societal Influences on the Utilization of Contraception Amongst Women in South Africa
}

\author{
Maureen Nokuthula Sibiya ${ }^{1}$, Dorinda Borg ${ }^{2}$, Shanaz Ghuman ${ }^{3}$, Poovendhree Reddy ${ }^{3}$, Thembilihle Ngxongo ${ }^{4}$, \\ Firoza Haffejee $^{5}$, Nalini Govender ${ }^{5} \&$ Laura O'Connor ${ }^{6}$ \\ ${ }^{1}$ Faculty of Health Sciences, Durban University of Technology, Durban, South Africa \\ ${ }^{2}$ Department of Somatology, Durban University of Technology, Durban, South Africa \\ ${ }^{3}$ Department of Community Health Studies, Durban University of Technology, Durban, South Africa \\ ${ }^{4}$ Department of Nursing, Durban University of Technology, Durban, South Africa \\ ${ }^{5}$ Department of Basic Medical Sciences, Durban University of Technology, Durban, South Africa \\ ${ }^{6}$ Department of Chiropractic, Durban University of Technology, Durban, South Africa \\ Correspondence: Maureen Nokuthula Sibiya, Faculty of Health Sciences Durban University of Technology, P.O. \\ Box 1334, Durban, 4000, South Africa. Tel: 27-31-373-2704. E-mail: nokuthulas@dut.ac.za
}

\author{
Received: October 14, 2019 Accepted: November 17, 2019 Online Published: January 30, 2020 \\ doi:10.5539/gjhs.v12n2p41 URL: https://doi.org/10.5539/gjhs.v12n2p41
}

\begin{abstract}
The strong desire to experience motherhood, mediated by prevailing social and cultural norms encourage childbearing in society. Contraceptive use and pregnancy among HIV positive women in South Africa is of growing concern as it may be associated with various adverse factors having socio-economic and health impacts. The timeous initiation and optimal utilisation of antenatal care services is imperative to ensure positive pregnancy outcomes and good maternal health; not always possible due to various challenges in developing countries. Motherhood is a component of a women's identity in cultural societies and important for female social status. Major challenges are gender-based violence and gender inequality as well as physiological factors that place women at risk like cultural and behavioural practices requiring parental consent for access to reproductive and sexual health services tend to discourage girls and women in their pursuit for decision making in reproductive health. This study examines the societal influences on contraceptive usage amongst women attending an antenatal clinic, their contraceptive use and HIV status in the city of Durban, province KwaZulu-Natal, South Africa. A cross-sectional study was conducted at a Primary Health Care (PHC) facility with a total of 283 pregnant women in trimester one visiting the antenatal clinic for the first time who completed a self-administered questionnaire. Results evidenced that almost $70 \%$ of the study population are aware of their HIV status prior to conceiving. Contraceptive usage in HIV positive participants was similar $82(81 \%)$ to $97(75 \%)$ in HIV negative participants. The HIV positive participants were aware of the consequences of non-contraceptive use. HIV positive women were not deterred by the desire to use contraception nor conceive (OR: 1.04, CI: $0.61-1.79$ ). The study reports a high number of the women are single ( $>75 \%)$, low level of education $(90 \%)$, unemployed $(>70 \%)$. HIV status has no impact on contraceptive use and the prevalence of pregnancy among HIV positive women. The number of miscarriages $(11 \%)$ and early neonatal deaths $(6 \%)$ reported appeared higher in HIV positive women. Smoking $(>50 \%)$ and alcohol consumption $(>50 \%)$ were equally high amongst the pregnant women. Comprehensive programs for planned pregnancies in HIV positive women is necessary for a paradigm shift in the prevailing social and cultural norms worldwide. Reproductive health education extending to embrace the boys and men in the population will increase the importance and acceptance of contraception usage for both HIV positive and negative women in reproductive health care.
\end{abstract}

Keywords: societal influences, contraceptive use, pregnancy, HIV status

\section{Introduction}

The utilization of contraceptives in a South African context is important in maintaining and promoting access to sexual and reproductive health care services in accordance with the Sustainable Development Goal 3.7 for 2030 (United Nations [UN], 2014). However, like South Africa, developing countries possess many factors which negatively influence the utilization of contraception amongst marginalized women, in the context of socio 
demographic, family and/or partner support and life style factors (Graham et al., 2016; Kruk et al., 2016; Mark, 2007). These factors may delay the United Nation Population Fund (UNFPA) vision of achieving zero percent unmet need for family planning (UNFPA, 2018) by 2030 which currently is $12 \%$. As reported in the Sustainable Development Goals (3.7 Target 5B) that only 50\% of women in developing areas received the recommended amount of reproductive health care. Koblinsky et al. (2016) reported that in sub-Saharan Africa death due to pregnancy and childbirth is still 100 times more than developed countries. Therefore, the Official Development Assistance for family planning and reproductive health care still remains low (UN, 2014).

In developing countries the access to antenatal care has increased to $83 \%$ in 2012 (UN, 2014). In Africa, particularly South Africa, as stated by the South African Demographic and Health Survey (SADHS) report released in 2017, the usage of contraception remains low around 58.3\% (SADHS, 2016). According to Ceshia \& Horton, (2016) there is a need for international health care providers to fundamentally reappraise sustainable maternal wellbeing and healthcare practices, programmes and policies. This study explored women's reproductive intentions and the factors influencing their contraceptive choices at a public health facility in KwaZulu-Natal (KZN) providing services to pregnant women in particular with regard to contraceptive usage and HIV status. Major challenges regarding sexual and reproductive health care in women include socio-demographic factors (age, marital status, employment, household income, and living conditions), family/partner support and lifestyle factors that place women at risk for contraceptive utilization and decision making practices.

Considering the extent of the HIVAIDS epidemic (Varas-Diaz et al., 2019; World Health Organization [WHO], 2018) options of reproductive intent and choice in HIV positive women is important to warrant the provision of suitable reproductive health care services. In sub-Saharan Africa, women in their reproductive years are the majority of HIV positive (UNAIDS Global Report, 2018) in addition a high percentage are young females (National Department of Health South Africa. Annual Report 2017/2018). Internationally, but more so in developing countries, the focus of most health services are on HIV positive people by providing services to manage opportunistic infections and the provision of antiretroviral treatment (ART) (Harper et al., 2007). South Africa has the highest HIV epidemic profile in the world, with an estimated 7 million people living with HIV in 2017. South Africa has made some progress in managing the HIV/AIDS epidemic since 2008, as the uptake of antiretroviral treatment has increased dramatically to 1900 000. However, the Department of Health, South Africa (DoHSA, 2018), reported South Africa as having one of the fastest growing HIV epidemics. The prevalence among pregnant women alone increased from less than 1\% in 1990 to 30\% in 2005 (DoHSA, 2018). This dramatic increase in HIV infection rates has resulted in the country having the largest population of HIV positive people in the world, (5.5 million people) (Aryeetey et al., 2010) with approximately one in eight of its population infected with HIV. In South Africa, the pattern of HIV infection in KwaZulu-Natal province reports 40.8\% [39.5-42.1\%] of adults (aged 15 years and older) are living with HIV DoHSA (Thornton et al., 2004).

Appropriate reproductive health services for pregnant HIV positive females has not received much consideration (Barot, 2017). Perinatal HIV infection, re-infection with various strains of viral HIV, including substantial risk for sexual transmission is associated with the use of unprotected sexual activity and irresponsible contraceptive use (Sajow, 2019; Mayondi et al., 2016; Koblinsky et al., 2016). Reproductive health care policies do not support HIV positive individuals from reproducing (Kass, 2004). People's perceptions and views regarding HIV and reproduction has generally been associated with stigma and discrimination (UN, 2014). Due to the high health risks, a few HIV positive people may opt not to conceive, however, the influence by social values that encourage childbearing may instil strong personal desires to experience biological parenthood (Cooper et al., 2007; 2009). Evidence from both developing and developed countries, show that a considerable number of HIV positive females continue to want children in spite of their status (Duarte et al., 2014; Suryavanshru et al., 2008; Kirshenbaum et al., 2004). Thus this study examined the societal influences on contraceptive usage amongst women attending an antenatal clinic, their contraceptive use and HIV status.

\section{Methods}

\subsection{Design and Setting}

A cross-sectional quantitative study was conducted amongst pregnant women to assess societal factors influencing contraceptive choices and reproductive intentions. The study was conducted at a Primary Health Care (PHC) facility in an urban area in the eThekwini District Municipality of KZN, which serves people from a disadvantaged socio-economic community including informal settlements. The health care facility predominantly serves black urban and peri-urban working class communities, and is broadly representative of the population of the province and the country.

\subsection{Ethics and Recruitment of Sampling Participants}


The study recruited a total of 283 pregnant women who presented at their first ANC visit to the clinic and who were in their first trimester of pregnancy at a public health facility providing antenatal care, HIV care and ART in the central Durban metropolitan area. Pregnant women accessing antenatal care (ANC) at the primary health care (PHC) facility were conveniently sampled to participate in the study. All pregnant women who presented for their first ANC visit at the PHC facility and were between 4 and 24 weeks of pregnancy were selected. At the beginning of the study, each participant signed informed consent. The researchers maintained confidentiality and privacy of all information. Ethical approval was granted by the Durban University of Technology Institutional Research Ethics Committee (IREC 034/14 and IREC 045/14) as well as gatekeeper permission was granted by the KwaZulu-Natal Department of Health (HRKM 234/14).

\subsection{Data Collection and Analysis}

Data was collected using a questionnaire. Each participant was afforded the right to complete questionnaires in the language of preference (English or isiZulu). Data that was collected was stored securely and no reference was made to participants' names in any research output. The following variables were included: socio-demographics, family/partner support, lifestyle, HIV status, contraceptive usage, antenatal health care.

Epidemiological screening and clinical data were analysed using STATA ${ }^{\circledR}$ version 15 . Frequency distributions of categorical variables and means, standard deviation and ranges of continuous variables were calculated. Bivariate associations between categorical variables like demographic and clinical variables stratified by HIV status were evaluated using the Pearson's Chi squared test and Fischer's exact test where applicable. HIV status was evaluated as a binary (HIV positive vs HIV negative variable). Odds ratios were calculated for binary outcome variables. Multivariate regression modelling was done in a backward stepwise method with the inclusion of relevant covariates. Ninety-five percent confidence intervals were calculated and probability levels of $p$-value $\leq 0.05$ were considered statistically significant.

\section{Results}

Table 1. Socio-demographic characteristics of the study population according to HIV status.

\begin{tabular}{|c|c|c|c|}
\hline Socio-demographic characteristics & n (\%) & $\begin{array}{l}\text { HIV - } \\
\text { n (\%) }\end{array}$ & $\begin{array}{l}\text { HIV + } \\
\text { n (\%) }\end{array}$ \\
\hline \multicolumn{4}{|l|}{ Age $(n=282)$} \\
\hline Under 18yrs & $17(6.0)$ & $14(8.8)$ & $3(2.4)$ \\
\hline $18-30 y r s$ & $206(73.1)$ & $125(78.6)$ & $81(65.9)$ \\
\hline$>30 \mathrm{yrs}$ & $59(21)$ & $20(12.6)$ & $39(31.7)$ \\
\hline \multicolumn{4}{|l|}{ Marital status $(n=273)$} \\
\hline Married / Living together & $48(17.5)$ & $30(19)$ & $18(15.7)$ \\
\hline Single & $221(81.0)$ & $125(79.1)$ & $96(84)$ \\
\hline Divorced/separated/widowed/other & $4(1.5)$ & $3(1.9)$ & $1(0.9)$ \\
\hline \multicolumn{4}{|l|}{ Level of education $(n=267)$} \\
\hline None & $9(3.4)$ & $3(2)$ & $6(5.2)$ \\
\hline Primary school & $8(3)$ & $3(2)$ & $5(4.3)$ \\
\hline High school & $250(93.6)$ & $145(96)$ & $105(90.5)$ \\
\hline \multicolumn{4}{|l|}{ Employment status $(n=271)$} \\
\hline Unemployed & $193(71.2)$ & $108(69.7)$ & $85(73.3)$ \\
\hline Vendor & $77(28.4)$ & $46(29.7)$ & $31(26.7)$ \\
\hline Housewife & $1(0.4)$ & $1(0.7)$ & $0(0)$ \\
\hline \multicolumn{4}{|l|}{ Living category $(n=264)$} \\
\hline Renting/living with partner & $96(36.4)$ & $54(36)$ & $42(36.8)$ \\
\hline Relatives & $77(29.2)$ & $47(31.3)$ & $30(26.3)$ \\
\hline
\end{tabular}




\begin{tabular}{llll}
\hline Friends & $62(23.5)$ & $31(20.7)$ & $31(27.2)$ \\
Hostel & $22(8.3)$ & $13(8.7)$ & $9(7.9)$ \\
Squatter & $7(2.7)$ & $5(3.3)$ & $2(1.8)$ \\
\hline Household income (Rands) $(n=110)$ & & & \\
$<$ R1500 & $71(64.6)$ & $40(60.6)$ & $31(70.5)$ \\
R1501 to 3000 & $20(18.2)$ & $12(18.2)$ & $8(18.2)$ \\
$>$ R3000 & $19(17.3)$ & $14(21.2)$ & $5(11.4)$ \\
\hline
\end{tabular}

Table 2. Contraceptive use in the study population prior to pregnancy according to HIV status

\begin{tabular}{|c|c|c|c|}
\hline & n (\%) & $\begin{array}{l}\text { HIV - } \\
\text { n (\%) }\end{array}$ & $\begin{array}{l}\text { HIV + } \\
\text { n (\%) }\end{array}$ \\
\hline HIV status demographics & 283 & $160(57 \%)$ & $123(44 \%)$ \\
\hline Contraception & 231 & $97(74.6)$ & $82(81.2)$ \\
\hline \multicolumn{4}{|l|}{ Contraceptive use } \\
\hline \multicolumn{4}{|l|}{ Type of contraceptive $(\mathrm{n}=231)$} \\
\hline Condom use & $80(34.6)$ & $40(30.8)$ & $40(40)$ \\
\hline Injectable & $55(23.8)$ & $32(24.6)$ & $23(22.8)$ \\
\hline $\begin{array}{l}\text { Other methods used: IUD, pill, withdrawal, implants, } \\
\text { spermicidal, traditional }\end{array}$ & $44(19.1)$ & $25(19.2)$ & $19(18.8)$ \\
\hline No contraceptive used & $52(22.5)$ & $33(25.4)$ & $19(18.8)$ \\
\hline \multicolumn{4}{|l|}{ Reasons for non-contraceptive use ( $n=232)$} \\
\hline Did not mind if they fell pregnant & $76(32.8)$ & $42(31.1)$ & $34(35.1)$ \\
\hline Thought that could not get pregnant at the time & $80(34.5)$ & $50(37.0)$ & $30(31)$ \\
\hline Concerned about side effects of using a contraception & $26(11.2)$ & $16(11.9)$ & $10(10.3)$ \\
\hline Difficulty accessing contraceptives & $5(2.2)$ & $4(3.0)$ & $1(1.0)$ \\
\hline Thought that either their partner or themselves was sterile & $4(1.7)$ & $0(0)$ & $4(4.1)$ \\
\hline Refusal by partner & $7(3.0)$ & $4(3.0)$ & $3(3.1)$ \\
\hline Religious beliefs & $2(0.9)$ & $0(0)$ & $2(2.1)$ \\
\hline Other & $32(13.8)$ & $19(14.1)$ & $13(13.4)$ \\
\hline
\end{tabular}

Table 3. Association between HIV positive status and the decisions in the use of contraceptives

\begin{tabular}{lll}
\hline & \multicolumn{2}{l}{ HIV+ status } \\
\cline { 2 - 3 } & OR & $\mathbf{9 5 \%} \mathbf{~ C I}$ \\
\hline Condom use & 1.52 & $0.89-2.58$ \\
Injectable contraceptive & 0.98 & $0.54-1.75$ \\
IUD/pill/implant/withdrawal/spermicidal & 1.35 & $0.49-3.72$ \\
I did not mind if I got pregnant & 1.04 & $0.61-1.79$ \\
I thought I could not get pregnant & 0.71 & $0.41-1.22$ \\
I had side effects from use of contraceptives & 0.89 & $0.39-2.00$ \\
\hline
\end{tabular}


Table 4. Factors influenced by culture and behaviour on decision making of pregnant women.

\begin{tabular}{llll}
\hline \multirow{2}{*}{ Decision making and behavioural factors } & Total respondents & HIV - & HIV + \\
\cline { 2 - 4 } & $* \mathrm{~N}(\%)$ & $\mathrm{n}(\%)$ & $\mathrm{n}(\%)$ \\
\hline Pregnancy HIV status & 63 & $32(50.7)$ & $31(49.3)$ \\
\hline History of Pregnancy: & & $0(98.0)$ & $1(2.0)$ \\
Number of abortions & 54 & $4(7.4)$ & $6(11.1)$ \\
Number of miscarriages & & $0(98.0)$ & $1(2.0)$ \\
Number of stillbirths & & $1(94.0)$ & $3(6.0)$ \\
Early neonatal deaths & & & \\
\hline Lifestyle Behaviours: & 73 & $37(51.0)$ & $36(49.0)$ \\
Smoking & & $37(51.0)$ & $36(49.0)$ \\
Alcohol consumption & & 0 & 0 \\
Drug dependency & & & \\
\hline Family/partner support & 71 & $25(35.2)$ & $20(28.2)$ \\
Needs support & 75 & $34(45.3)$ & $32(42.7)$ \\
Receiving support & 75 & $33(44.0)$ & $31(41.3)$ \\
Satisfied with support & & & \\
\hline
\end{tabular}

*Not all participants answered all questions.

\section{Findings and Discussion}

Table 1 provides the data on the demographic characteristics of the study population according to the HIV status. Of the 283 responses to HIV status, it was reported that 123 (43.5\%) pregnant women were HIV positive. In relation to age and HIV status, the higher prevalence was reported in the age category of 18 to 30 years 206 (73\%). In terms of employment status, $193(71 \%)$ were unemployed. Most women who were HIV positive were single 96 (84\%). Of the pregnant women, 71 (65\%) resided in households, where the income was less than R1500 per month. A larger proportion of the participants either lived with their partner $96(36 \%)$ or with a relative $77(29 \%)$.

Table 2 provides the data on the contraceptive use in the study population according to the HIV status. Contraceptive usage in HIV positive participants was higher at 82 (81\%) as compared to 97 (75\%) in HIV negative participants. Condom usage is reported to be the most popular method of contraceptive $80(35 \%)$, followed by the contraceptive injection 55 (24\%). However, 23 (23\%) of all participants reported that they did not use any form of contraception. Difficulty accessing contraception and services $5(2 \%)$ was not reported to be a main reason for non-use of contraception. The study reported that the main reasons that they could not conceive at that point in time as the most common reason for non-contraceptive use was $80(35 \%)$. The HIV positive participants appear to be aware of the consequences of non-contraceptive use and the number of participants among HIV positive contraception is only $19(19 \%)$.

Table 3 presents results from multivariate analyses of HIV positive women and the association on decisions on reasons for the use of contraception. Condoms had an OR: 1.52, CI: $0.89-2.5$; followed by the IUD, pill, implant, withdrawal and spermicidal forms (OR: 1.35, CI: 0.49 - 3.72) of contraception were the most utilised methods. Being HIV positive did not deter the desire of women to conceive (OR: 1.04, CI: 0.61 - 1.79). The lack of knowledge with perceived side-effects, fears and misinformation are a huge barrier to contraceptive use. This was found in studies by Campbell et al., (2006) and Eaton et al., (2003).

In Table 4, the decision making and history of the pregnant women and lifestyle behaviors as well the support they received are presented. A number of challenges impacting on contraceptive use are reported for pregnant women. This study includes HIV status, education, socioeconomic status, partner support household circumstances, pregnancy history; factors that place women at risk due to cultural and behavioural practices for access to reproductive and sexual health services. These tend to discourage women in their pursuit for reproductive health and well-being. Various studies have shown that the higher the education levels the more likely modern contraception methods usage would occur (Asekun-Olarinmoye, 2013; Palamuleni, 2013; Teye, 2013; 
Onwujekwe, 2012). Whilst studies do report education is important and usage was high (Aryeetey et al., 2010; Moronkola et al., 2006); the knowledge of family planning and contraception side-effects in another study found women had low contraceptive use (Hagan \& Buxton, 2012; Ujboaja, 2011). The number of miscarriages (11\%) and early neonatal deaths $(6 \%)$ reported appeared higher in HIV positive women. The influence by social values that encourage childbearing may instil strong personal desires to experience biological parenthood (Cooper et al., 2007; 2009).

Motherhood is a norm for married women in society (Kirshenbaum et al., 2004), and in predominantly pro-natal cultures such as in Latin America Africa and Asia, the pressure on females to produce children is generally great. Cultural beliefs imposed on women and their fertility, provide a higher substantial social status to womenfolk who have children, while barrenness may convey adverse social consequences (Doyal \& Anderson, 2005). A South African study by Peer et al. (2016), reports higher self-esteem and confidence as a promotor for contraceptive use and reproductive decision making.

From the sample of 283 pregnant women 123 (44\%) were found to be HIV positive. Socio-demographic factors such as education levels, living conditions and household income of the participants appeared to have little significance with regards to their HIV status. Some HIV positive individuals however do wish to avoid pregnancy. Fears of partner and infant infection and having a previously HIV infected baby are some of the important factors deterring individuals from being pregnant. There is strong disapproval associated with HIV and reproduction. Family, husbands, partners and societal expectations for childbearing have an influence on women's reproductive intentions, and HIV status may be a factor discouraging reproduction.

The demographic characteristics of the study population according to the HIV status. Of the total responses to HIV status, it was reported that just under half of the pregnant women were HIV positive. HIV status was found to be more prevalent in the age category 18 to 30 years with two thirds of these participants being unemployed. Most of the women who were HIV positive were single. A study by Cox et al. (2013), reported that decisions regarding family planning were strongly related to being married and marital satisfaction. Of the pregnant women, more than half resided in households, where the income was less than R1500.00 per month. A larger proportion of the participants either lived with their partner or with a relative. Men's perceptions, support and communication with their partners positively influenced contraceptive use (Anguzu et al., 2014). Similarly, poor communication and support was found to be associated with low contraceptive use (Audu, 2008; Iklaki, 2005).

Contraceptive usage in HIV positive participants was high as compared to that in HIV negative participants. Condom usage is reported to be the most popular method of contraceptive, followed by the contraceptive injection. A quarter of all participants reported that they did not use any form of contraception. The study reported that the main reason that they could not conceive at that point in time was the most common reason for non-contraceptive use. The HIV positive participants appear to be aware of the consequences of non-contraceptive use. An HIV positive status does not remove sexual and reproductive desires; therefore, diversity exists in reproductive and contraceptive intentions.

As described in the UNAIDS Report (2017/2018), in sub Saharan Africa, more than 50\% of HIV-positive women have discussed family planning with a health care provider at a family planning clinic. In these and other African settings, few couples employ more than one protection method (using condoms alongside another contraceptive method). This study found that amongst HIV positive women the use of condoms, IUD, pill, implant, withdrawal and spermicidal forms of contraception are the most utilised methods.

In various African countries the needs for contraception are still unmet. Studies in South Africa and Kenya explored perceptions about having a child irrespective of HIV transmission risk and interventions for safer conception (Cooper et al., 2007; 2009). Pregnancy was more often desired by the women for various reasons of which there was no concern of transmitting HIV onto their unborn babies. Those participants who were not planning a pregnancy, a minority were using protection. Protection included condom use (protective against transmission of HIV and sexually transmitted infections), other contraceptive methods whose effectiveness is not reliant on it being used at the time of sex; for example pills, injections, implants and intrauterine devices. There is an emphasis on condoms in HIV services with a risk that participants exaggerated their use of condoms. The unmet family planning need is actually greater than the estimate. Condom use may be over-reported. This group of women with HIV wishing to delay or avoid pregnancy, most have unmet family planning needs. Another unmet need would be the family planning information provided by health care workers.

Contraceptive options were important as HIV infected women have specific needs and family planning options based on their HIV sero-status. Without intervention HIV positive mothers can transmit the infection to their baby by the time it is born, in accordance with the WHO Report, (2018). Some women want a child to leave behind as 
some form of legacy or reminder; a partner might insist on having a baby, with the woman too afraid to disclose her status (Akatukwasa et al. 2019). The community, and fear of stigma and discrimination. Similarly, other studies by King et al. (2011) also reported concerns that most of the women were not practicing safe sex, despite receiving extensive family planning advice. These ages of onset of sexual activity appears to fall within the National norm of 15-24 years (Beksinska et al., 2014). Of those respondents, the first use of contraception was similar and relatively high. The average age of the HIV negative participants was similar, 20 as compared to $19.3 \%$ respectively.

The study reported that most of this study population where aware of their HIV status prior to falling pregnant. Our findings show that HIV status appears not to significantly influence the choice of these women to become pregnant and their desire to become a mother is high (Duarte et al, 2014; Kirshenbaum et al., 2004). As the literature suggests, not having a child may be viewed negatively within their social and cultural context as high importance is placed on a woman's fertility. Hence it may influence their decision to conceive. A systematic review by Blackstone et al. (2017), on twelve Sub-Saharan African studies reported that negative factors affecting contraceptive use included social/cultural norms on fertility, women's misconceptions of contraceptive side-effects and male-partner disapproval predominantly. The positive factors included employment, communication and support from partners, and education.

\subsection{Limitations}

The participants represented in this study were of those who attended the clinic, however due to circumstances some of the pregnant mothers did not continue with follow up and many of the participants dropped out of the study. Due to the nature of the questions some participants, declined to participate in the study.

\subsection{Recommendations}

The transition from the Millennium Developmental Goals (MDG's) to the Sustainable Development Goals (SDG's) highlights the closure of the $50 \%$ gap in reproductive health care provision for women in developing countries. This study has shown that although variations of societal influences for contraceptive utilization are found across the world, in the African continent, and in South Africa; the challenges and barriers to contraception uptake and utilization remain a multifaceted problem. We recommend the role of health professionals in broader social systems and community interventions targets working within these cultural constraints and counteracting the misinformation and negative perceptions. Upscaling our existing reproductive health care system by providing knowledge on the availability and provision of services including access for all at the various levels of the health care system.

\section{Conclusion}

Although it is generally accepted that all women have the right to bear children, society finds it harder to accept when women living with HIV choose to do so. The study has shown HIV status has no impact on contraceptive use and the prevalence of pregnancy among HIV positive women with in this study population. That knowledge of HIV status, family planning and contraceptives does not equate effective decision making practices. This may be attributed to the pressure of cultural and social norms expected of them. The literature also shows that women are still falling pregnant. Perhaps further studies on sourcing data to ascertain whether women have a concern with transferring the HIV virus to their unborn children is a future research. It is intended that this research will address gaps in knowledge and inform the development of policy and programs to support safer and healthier reproductive options among HIV positive individuals in this developing country setting.

\section{Acknowledgements}

The researchers would like to acknowledge the following for their contributions towards the study; the Medical Research Council for the funding to conduct the research, Kwa-Zulu Natal Department of Health and Cato Manor Clinic staff for access to data for collection.

\section{Competing Interests Statement}

The authors declare that they have no competing interests.

\section{References}

Akatukwasa, C., Bajunirwe, F., Nuwamanya, S., Kansime, N., Aheebwe, E., \& Tamwesigire, I. K. (2019). Integration of HIV-Sexual Reproductive Health Services for Young People and the Barriers at Public Health Facilities in Mbarara Municipality, Southwestern Uganda: A Qualitative Assessment. International Journal of Reproductive Medicine, 2019, 1-11, 6725432. https://doi.org/10.1155/2019/6725432

Aryeetey, R., Kotoh, A. M., \& Hindin, M. J. (2010). Knowledge, perceptions and ever use of modern 
contraception among women in the Ga East District, Ghana. African Journal of Reproductive Health, 14, 26-31.

Asekun-Olarinmoye, E. (2013). Barriers to use of modern contraceptives amongst women in an inner city area of Osogbo metropolis, Osun State, Nigeria. International Journal of Reproductive Health, 5, 647-655. https://doi.org/10.2147/IJWH.S47604

Anguzu, R. (2014). Knowledge and attitudes towards use of long acting reversible contraceptives among women of reproductive age in Lubaga division, Kampala District, Uganda. BMC Research Notes, 7, 153. https://doi.org/10.1186/1756-0500-7-153

Audu, B. M. (2008). Attitude of Nigerian women to contraceptive use by men. Journal of Obstetrics and Gynecology, 28(6), 621-625. https://doi.org/10.1080/01443610802283530

Beksinska, M. E., Pillay, L., Milford, C., \& Smit, J. A. (2014). The sexual and reproductive health needs of youth in South Africa - history in context. South African Medical Journal, $104,10$. https://doi.org/10.7196/SAMJ.8809

Blackstone, S. R., Nwaozuru, U., \& Iwelunnmor, J. (2017). Factors Influencing Contraceptive Use in Sub-Sharan Africa: A Systematic Review. International Quarterly of Community Health Education, 37(2), 79-91. https://doi.org/10.1177/0272684X16685254

Barot, S. (2017). In a state of crisis: Meeting the Sexual and reproductive health needs of women in humanitarian situations. Guttmacher Institute. Guttmacher Policy Review, 20, 1-12.

Campbell, M., Sahin-Hodogglugil, N. N., \& Potts, M. (2006). Barriers to fertility regulation: A review of the literature. Studies of Family Planning, 37(2), 87-89. https://doi.org/10.1111/j.1728-4465.2006.00088.x

Ceshia, A., \& Horton, R. (2016). Maternal Health: time for radical reappraisal. The Lancet, 388(10056), 2064-2066. https://doi.org/10.1016/S0140-6736(16)31534-3

Cooper, D., Harries, J., Myer, L, Orner, P., \& Bracken, H. (2007). 'Life is still going on': Reproductive intentions among HIV-positive women and men in South Africa. Social Science and Medicine, 65, $274-283$. https://doi.org/10.1016/j.socscimed.2007.03.019

Cooper, D., Moodley, J., Zweigenthal, V., Bekker, L. G., Shah, I., \& Myer, L. (2009). Fertility intentions and reproductive health care needs of people living with HIV in Cape Town, South Africa: Implications for Integrating Reproductive Health and HIV Care Services. AIDS Behavior, 13, 538-546. https://doi.org/10.1007/s10461-009-9550-1

Cox, C. M. (2013). Understanding couple's relationship quality and contraceptive use in Kumasi, Ghana. International Perspectives of Sexual Reproductive Health, 39(4), 185-194. https://doi.org/10.1363/3918513

Doyal, L., \& Anderson, J. (2005). 'My fear is to fall in love again...' How HIV-positive African women survive in London. Social Science and Medicine, 60, 8. https://doi.org/10.1016/j.socscimed.2004.08.041

Duarte, M.T.C., Garcia de Lima Parada, C.M., \& do Rosário de Souza, L. (2014). Vulnerability of women living with HIV/aids. Revista Latino-Americano De Enfermagem, 22(1), 68-75. https://doi.org/10.1590/0104-1169.2837.2377

Eaton, L., Flisher, A. J., \& Aaro, L. E. (2003). Unsafe sexual behaviour in South African youth. Social Science and Medicine, 56(1), 149-165. https://doi.org/10.1016/S0277-9536(02)00017-5

Graham, W., Woodd, S., Byass, P., Filippi, V., Gon, G., Virgo, S., Chou, D., Hounton, S., Lozaro, R., Pattinson, R., \& Singh, S. (2016). Diversity and divergence: The dynamic burden of poor maternal health. The Lancet. Maternal Health Series, 1, 2164-2175. Department of infectious Disease Epidemiology, London School of Hygiene and Tropical Medicine, London, UK. https://doi.org/10.1016/S0140-6736(16)31533-1

Hagan, J. E., \& Buxton, C. (2012). Contraceptive knowledge, perceptions and use among adolescents in selected senior high schools in the central region of Ghana. Journal of Sociology Research, 3(2), 170-180. https://doi.org/10.5296/jsr.v3i2.2311

Harper, C., Blanchard, K., Newmann, S., Morar, N., \& Ramjee, G. (2008). Contraceptive counseling and care for HIV-infected and at-risk women in South Africa: A study of practices of health care providers. APHA Annual Meeting and Expo. San Diego, CA, USA.

Iklaki, C. U. (2005). Spousal communication in contraceptive decisions among antenatal patients in Calabar, south eastern Nigeria. Niger Journal Medicine, 14(4), 405-407. https://doi.org/10.4314/njm.v14i4.37197 
Kass, N. E. (2004). Policy, ethics and reproductive choice: Pregnancy and child-bearing among HIV-infected women. Acta Paediatrica Supplement, 400, 95-98. https://doi.org/10.1111/j.1651-2227.1994.tb13344.X

King, R., Khana, K., Nakayiwa, S., Katuntu, D., Homsy, J., Lindkvist, P., Johansson, E., \& Bunnell, R. (2011). 'Pregnancy comes accidentally - like it did with me': reproductive decisions among women on ART and their partners in rural Uganda. BMC Public Health, 11, 530. https://doi.org/10.1186/1471-2458-11-530

Kirshenbaum, S. B., Hirky, A. E., Correale, J., Goldstein, R. B., Johnson, M. O., Rotheram-Borus M. J., \& Ehrhardt A. A. (2004). "Throwing the dice": Pregnancy decision-making among HIV-positive women in four U.S. cities. Perspectives on Sexual and Reproductive Health, 36, 106-113. https://doi.org/10.1363/3610604

Koblinsky, M., Moyer, C. A., Calvert, C., Campbell, O. M. R., Feigi, A. B., Graham, W. J., ... Langer, A. (2016). Quality maternity care for every woman, everywhere: a call to action. The Lancet, 388: 2307-2320. Maternal Health Series 6. Department of infectious Disease Epidemiology, London School of Hygiene and Tropical Medicine, London, UK. https://doi.org/10.1016/S0140-6736(16)31333-2

Kruk, M. E., Kujawski, S., Moyer, C. A., Adamu, R. M., Afsana, K., Cohen, J., .. Yamey, G. (2016). The Lancet, 388: 2307-2320. Next generation maternal health: external shocks and health-system innovations. Maternal Health Series, 5, 2296-2306. Department of Global Health and Population, School of Public Health, HarvardTH Chan, Boston, MA, USA. https://doi.org/10.1016/S0140-6736(16)31395-2

Mark, K. E., Meinzen-Derr, J., Stephenson, R., Haworth, A., Ahmed, Y., Duncan, D., Westfall, A. \& Allen, S. (2007). Contraception among HIV concordant and discordant couples in Zambia: a randomized controlled trial. Journal of Women's Health (Larchmt), 16, 1200-1210. https://doi.org/10.1089/jwh.2006.0238

Mayondi, G. K., Wirth, K., Morroni, C., Moyo, S., Ajibola, G., Diseko, M., ... Lockman, S. (2016). Unintended pregnancy, contraceptive use, and childbearing desires among HIV-infected and HIV-uninfected women in Botswana: A cross-sectional study. BMC Public Health, 16(44), 1-10. https://doi.org/10.1186/s12889-015-2498-3

Moronkola, O. A., Ojediran, M. M., \& Amosu, A. (2006). A Reproductive health knowledge, beliefs and determinants of contraceptive use amongst women attending family planning clinics in Ibadan, Nigeria. African Health Sciences, 6(3), 155-159.

National Department of Health South Africa. Annual Report 2017/2018. (2018). A long and healthy Life for all South Africans. Health Systems Trust. RP327/2018 ISBN: 978-0-621-46663-8.

Onwujekwe, O. E. (2012). Increasing access to modern contraceptives: The potential role of community solidarity through altruistic contributions. International Journal of Equity and Health, 11(1), 34. https://doi.org/10.1186/1475-9276-11-34

Palamuleni, M. E. (2013). Socio-economic and demographic factors affecting contraceptive use in Malawi. African Journal of Reproductive Health, 17(3), 91-104.

Peer, N., Morojele, N., \& London, L. (2016). Factors associated with contraceptive use in a rural area in Western Cape Province. South African Journal of Medicine, 103(6), 406. https://doi.org/10.7196/SAMJ.6201

Sajow, H., Water, T., Hidayat, M., \& Holroyd, E. (2019). Maternal and reproductive health (MRH) services during the 2013 eruption of Mount Sinabung: A qualitative case study from Indonesia. Global Public Health, 1-15. https://doi.org/10.1080/17441692.2019.1657925

South Africa Demographic and Health Survey (SADHS). (2016). Report, National Department of Health (NDoH), Statistics South Africa (Stats SA), South African Medical Research Council (SAMRC), and ICF. 1-627.

Suryavanshi, N., Erande, A., Pisal, H., Shankar, A. V., Bhosale, R. A., Bollinger, R. C., Phadke, M., \& Sastry, J. (2008). Repeated pregnancy among women with known HIV status in Pune, India. AIDS Care, 20, 1111-8. https://doi.org/10.1080/09540120701842753

Teye, J. K. (2013). Modern contraceptive use among women in Suogyaman District of Ghana: Is reliability more important than health concerns? African Journal of Reproductive Health, 17(2), 58-71.

Thornton, A. C., Romanelli, F., \& Collins, J. D. (2004). Reproduction decision making for couples affected by HIV: A review of the literature. International AIDS Society, 12(2), 61-66.

Ujboaja, J. O. (2011). Contraceptive choices and practices among urban women in southeastern Nigeria. Nigerian Journal of Medicine, 20(3), 360-365.

United Nations Report. (2014). Human development Report 2014. Sustaining Human Progress: Reducing 
Vulnerabilities and Building Resilience, 1-239. UNDP.

UNAIDS Global Report: AIDS Epidemic. (2018). Joint United Nations Programme on HIV/AIDS. Retrieved 11 October, 2019 , from www.unaids.org/sites/default/files/en/media/unaids/contentassets/documents/epidemiology/2013/gr2013/U NAIDS_Global_Report_2018_en

UNAIDS. (2017). Confronting Discrimination. Overcoming HIV-related stigma and discrimination in health care settings and beyond. 1-62.

United Nations Population Fund (UNFPA). (2018). One Vision Three Zeros Annual Report 2018. Global Progress towards Sexual and Reproductive Health Zero unmet need for Family Planning. Retrieved 11 October, 2019, from https://www.unfpa.org/annual-report

Varas-Diaz, N., Rivera-Segarra, E., Neilands, T., Carminelli-Corretjer, P., Rivera, F., Varas-Rodriguez, E., \& Rivera-Diaz, M. (2019). HIV/AIDS stigma manifestations during clinical interactions with MSM in Puerto Rico. Journal of Gay and Lesbian Social Services, 31(2), 141-152. https://doi.org/10.1080/10538720.2018.1548325

World Health Organization (WHO). (2018). HIV/AIDS. Key facts. Retrieved from $\mathrm{http}: / /$ www.who.int/news-room/fact-sheets/detial/hiv-aids

\section{Copyrights}

Copyright for this article is retained by the author(s), with first publication rights granted to the journal.

This is an open-access article distributed under the terms and conditions of the Creative Commons Attribution license (http://creativecommons.org/licenses/by/4.0/). 